\title{
Supplementary figures of « The effects of ice and hillslope erosion and detrital transport on the form of detrital thermochronological age probability distributions from glacial settings"
}

\author{
Maxime. Bernard ${ }^{1}$, Philippe. Steer ${ }^{1}$, Kerry. Gallagher ${ }^{1}$, David. L. Egholm ${ }^{2}$ \\ ${ }^{1}$ Univ Rennes, CNRS, Géosciences Rennes, UMR 6118, 35000 Rennes, France. \\ ${ }^{2}$ Department of Geoscience, Aarhus University, Aarhus, Denmark.
}

Correspondence: Maxime Bernard (maxime.bernard@univ-rennes1.fr)

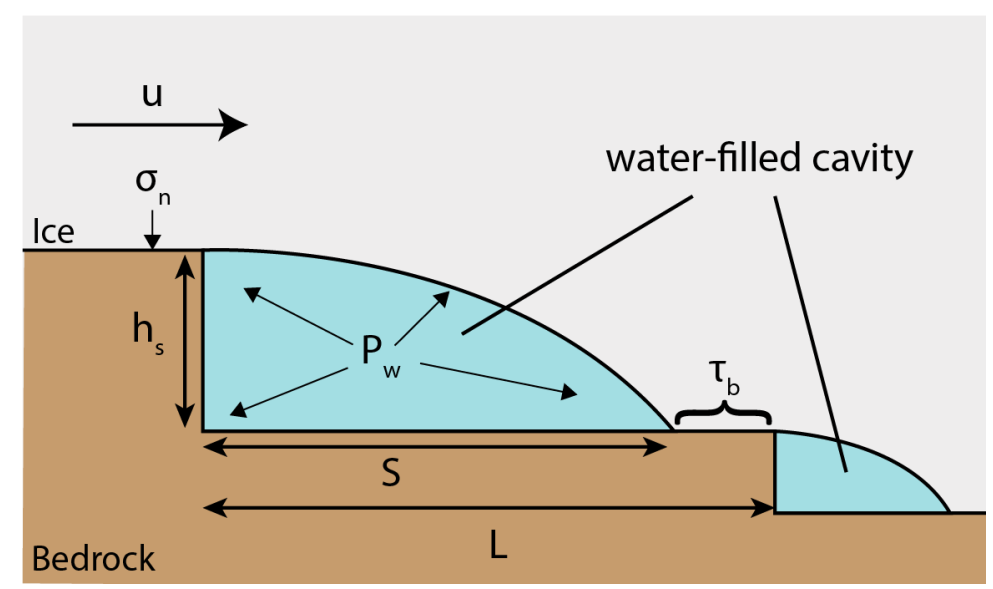

Figure S1: Flowing of ice over two bed steps. The geometry of cavities is defined by the height of the bed step $\left(h_{s}\right)$ and their length (S). $\mathrm{L}$ is the distance between two bed steps. The ice exerts normal pressure $\left(\sigma_{\mathrm{n}}\right)$ on the bed, where the ice-bed contact length is defined by $\mathrm{L}-\mathrm{S}$. The basal shear stress $\left(\tau_{\mathrm{b}}\right)$ is applied on this length. $\mathrm{P}_{\mathrm{w}}$ is the water pressure within a cavity. Modified after Iverson (2012).

(a)

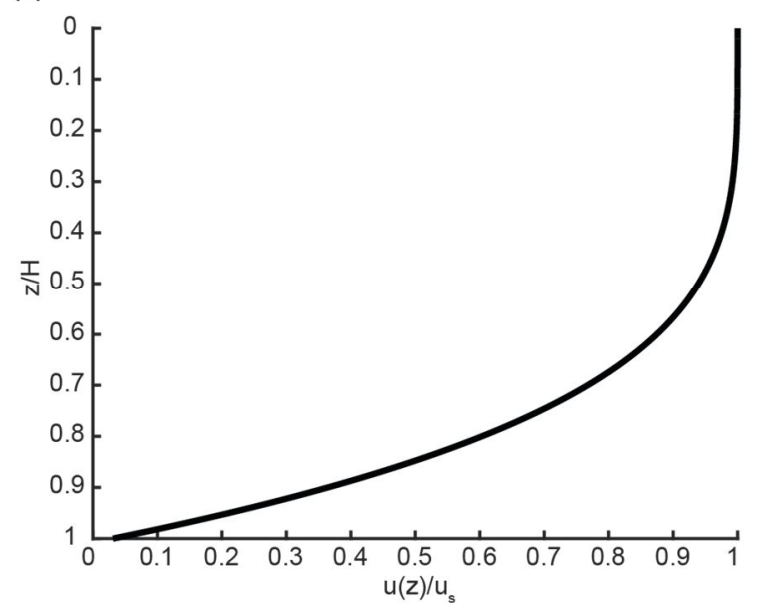

(b)

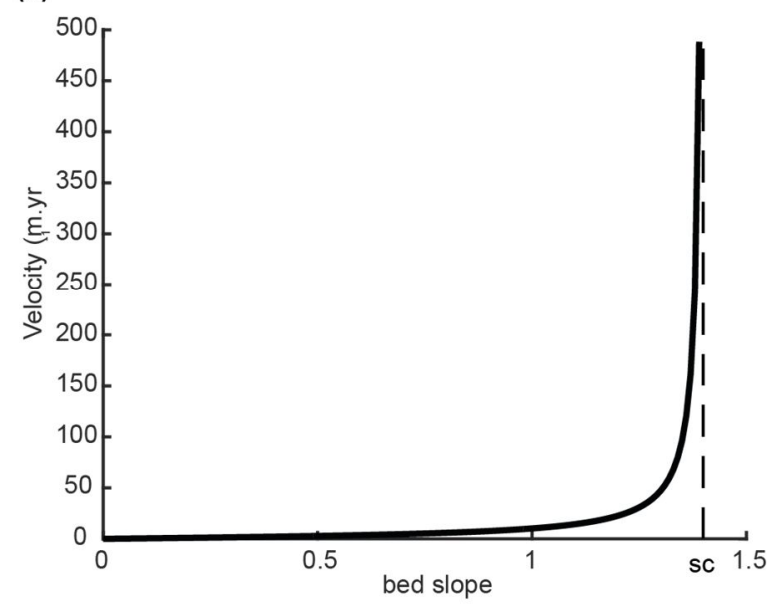

Figure S2: Velocity distribution for the glaciated particles (a) and particles located on hillslopes (b), $\mathrm{s}_{\mathrm{c}}$ is the critical slope. The parameters $\mathrm{z}$ and $\mathrm{H}$ are the vertical position of a particle in the ice and the ice thickness, respectively. The velocity of glaciated particles is denoted as $\mathrm{u}(\mathrm{z})$ and $\mathrm{u}_{\mathrm{s}}$ represent the ice surface velocity. 

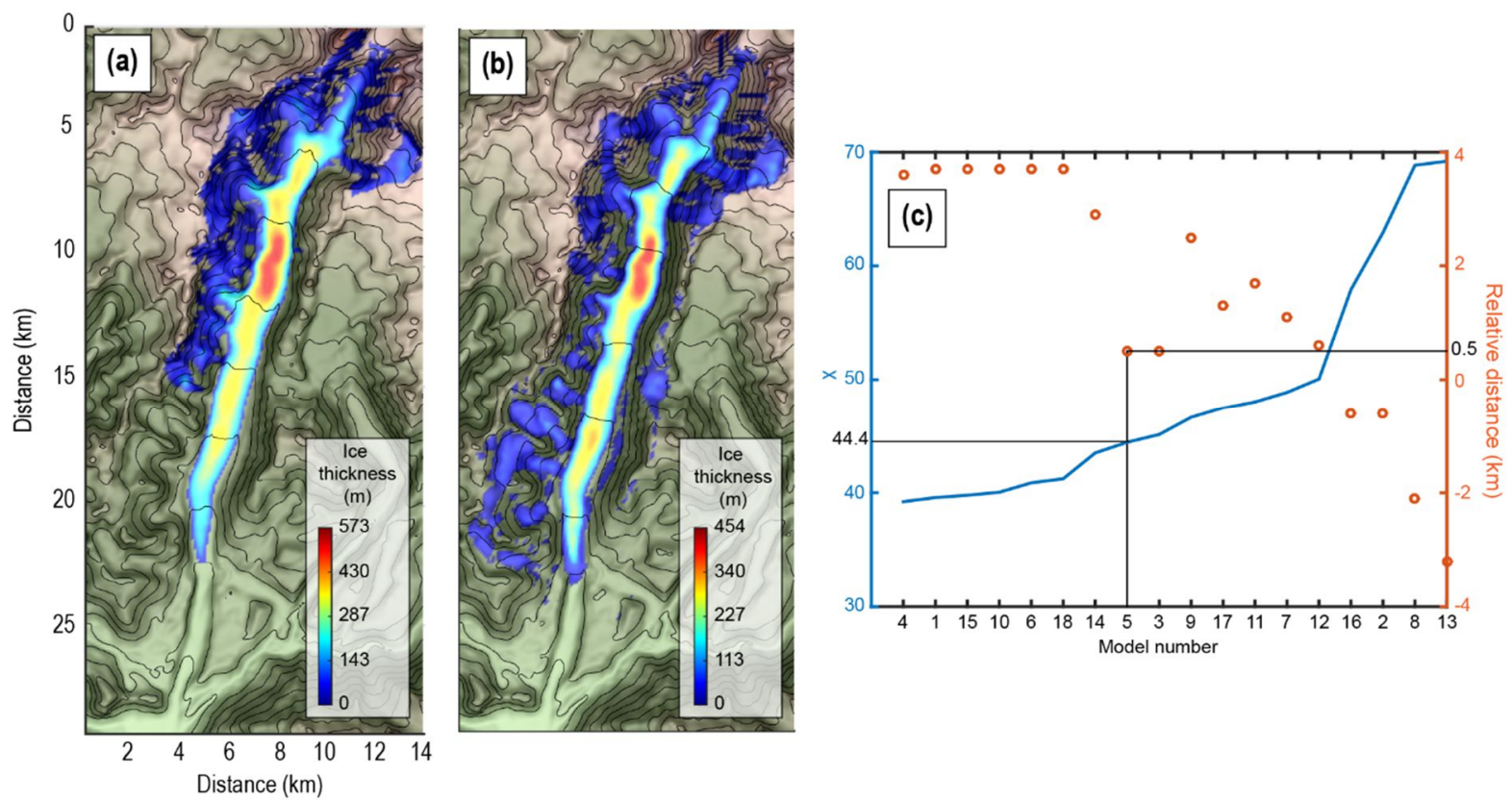

Figure S3: Calibration of the iSOSIA model of the Tiedemann glacier. (a) The ice thickness from the ITMIX experiments (Farinotti et al., 2017), (b) the ice thickness of the iSOSIA model, and (c) parameters space used for the calibration of the iSOSIA model. The two parameters are the chi value of the mean ice thickness difference between the iSOSIA and ITMIX models (blue curve), and the relative position of the glacier front of the iSOSIA model with the ITMIX results (orange circles). The iSOSIA model chosen is the model 5 as it shows the best compromise between the mean ice thickness difference (chi value) and the position of the glacier front compare to the ITMIX experiments results. 

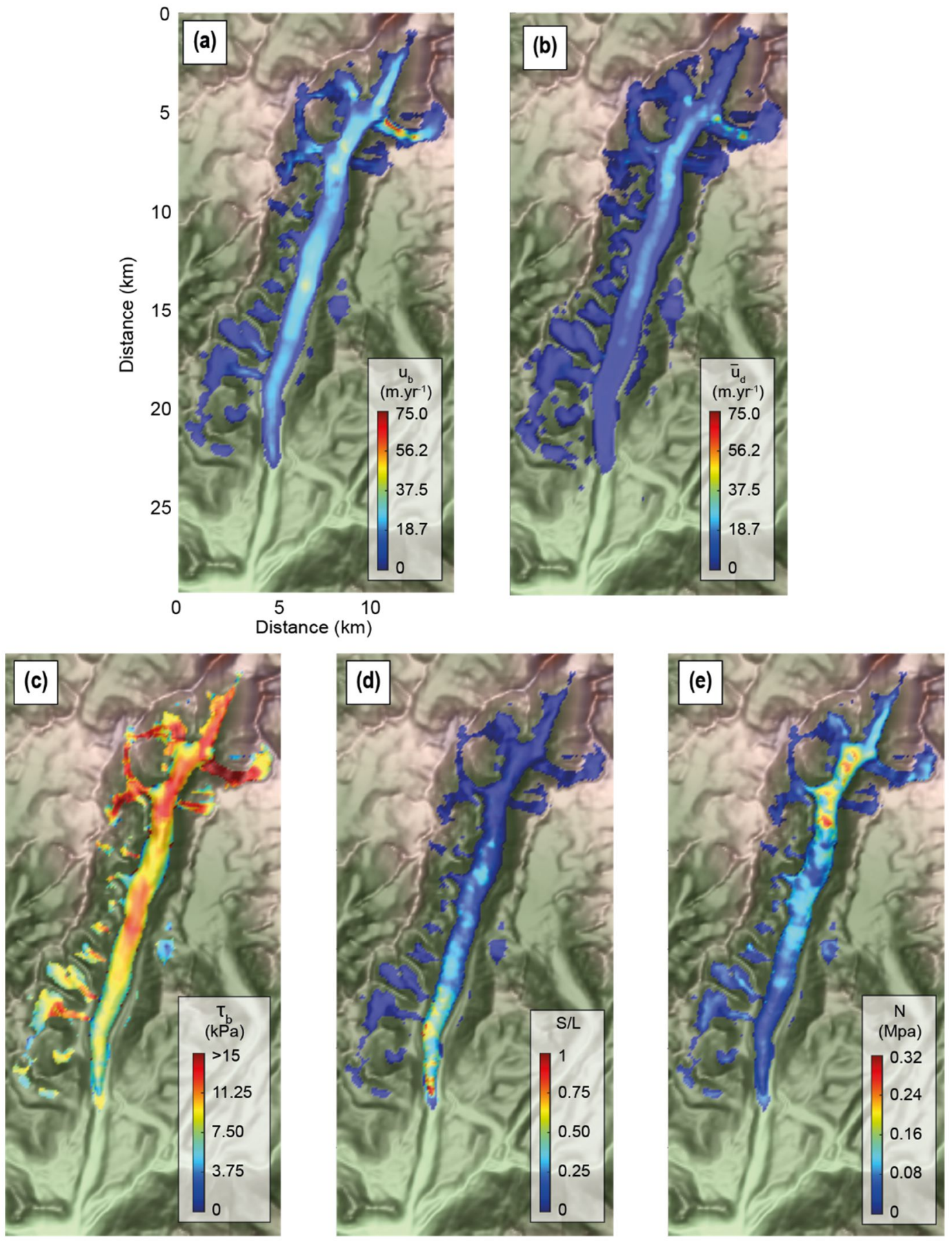

Figure S4: Spatial distribution of (a) the basal sliding speed, $\mathrm{ub},(\mathrm{b})$ the ice deformation speed, $\bar{u}_{d}$, (c) the basal shear stress, $\tau_{\mathrm{b}},(\mathrm{d})$ the opening cavity ratio, $\frac{S}{L}$, and (e) the effective pressure, N. S and L are the size of cavities and bed steps wavelength, see Fig. (S1). 
(a)

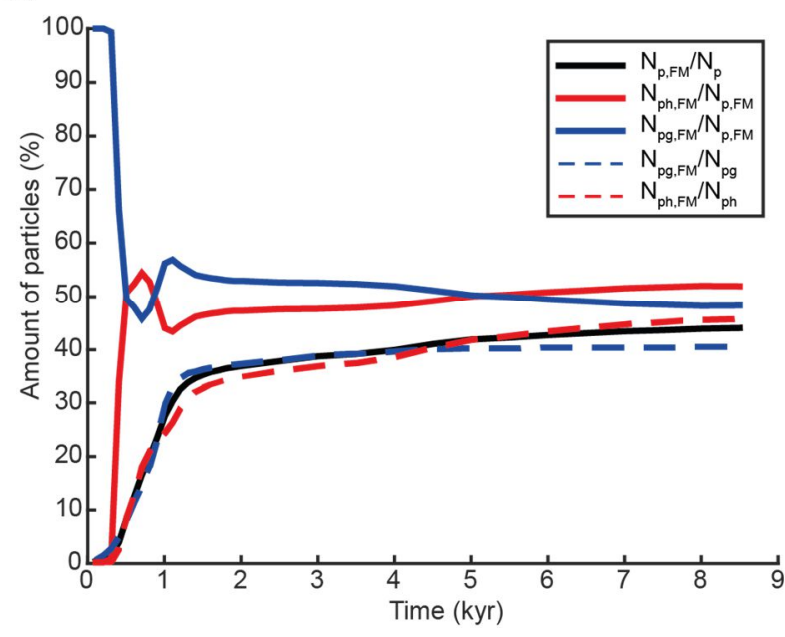

(b)

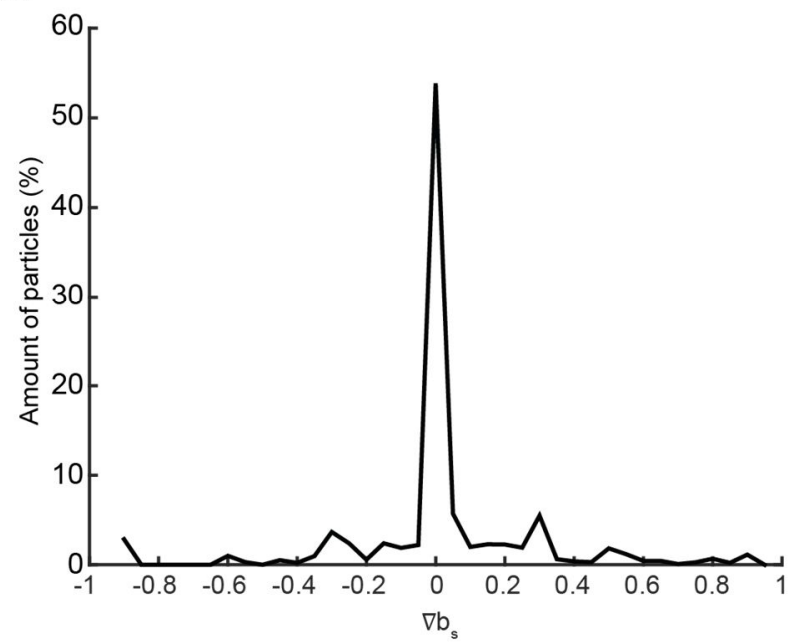

Figure S5: (a) Transient evolution of the number of particles in the frontal moraine. $\mathrm{N}_{\mathrm{p}}$ : total number of particles, $\mathrm{N}_{\mathrm{ph}}$ : total number of particle originated from hillslope, $\mathrm{N}_{\mathrm{pg}}$ : total number of particle originated from glaciers, $\mathrm{N}_{\mathrm{p}, \mathrm{FM}}$ : total number of particle in the Frontal Moraine (FM), $\mathrm{N}_{\mathrm{ph}, \mathrm{FM}}$ : number of hillslope-origin particle in $\mathrm{FM}$, and $\mathrm{N}_{\mathrm{pg}, \mathrm{FM}}$ : number of glacier-origin particles in FM. (b) Distribution of the bed slope in direction of sliding for tributary glacier carrying glaciated particles that remain close to their source after 8500 years of simulation.
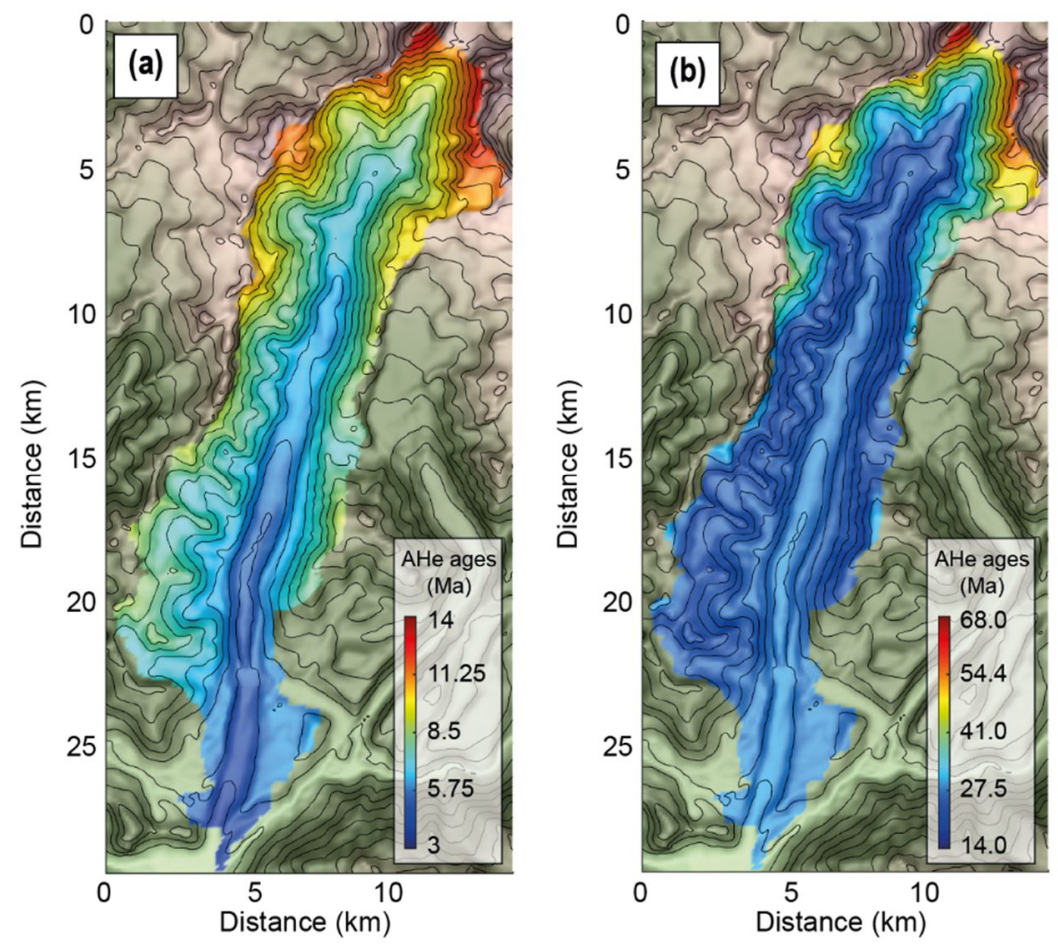

Figure S6: Spatial bedrock age distributions for the (a) AHe and (b) AFT systems. 

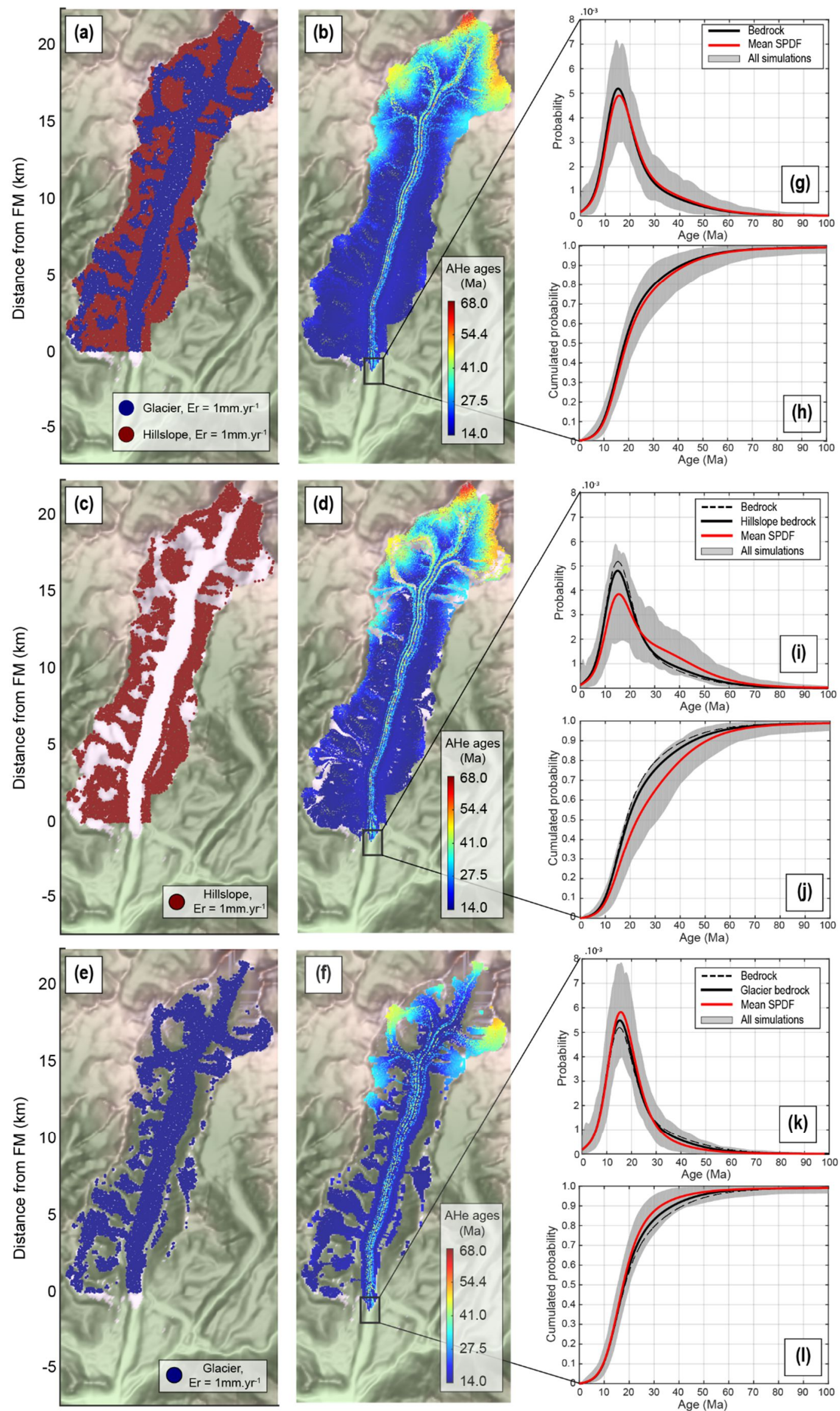
Figure S7: (a) Source of particles for the three models experiments: uniform sources of particles, (c) hillslope source of particles, and (e) glacier sources of particles, with Er is the erosion rate. Their respective spatial AFT ages distributions after $2000 \mathrm{yr}$ of particles transport are shown in b-d-f. Density plots and their cumulative distributions are shown in $\mathrm{g}-\mathrm{h}, \mathrm{i}-\mathrm{j}$, and $\mathrm{k}-\mathrm{l}$ respectively. The black squares show the frontal moraine (FM) position.
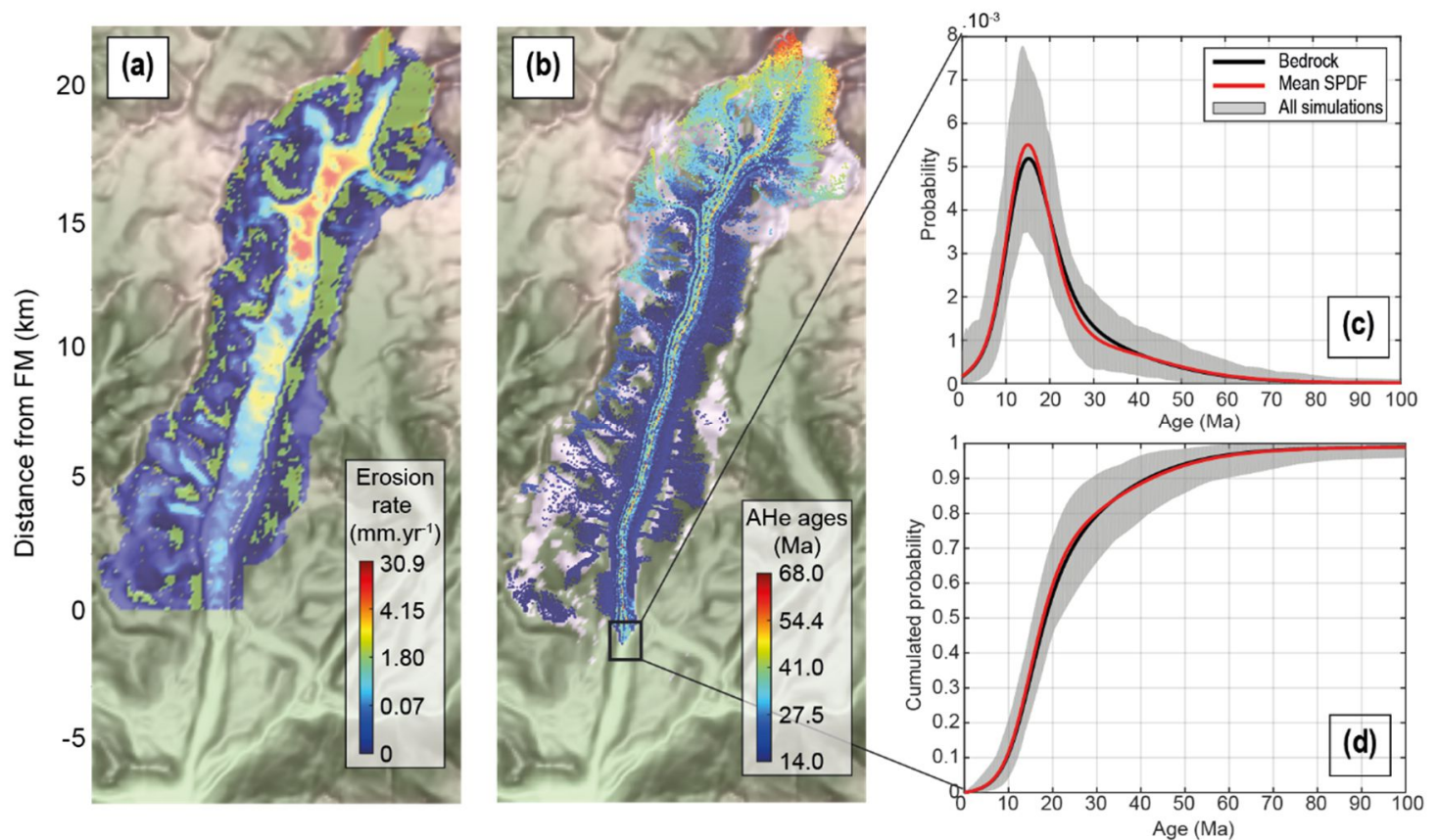

Figure S8: Non-uniform erosion model experiment, with the (a) erosion rate, (b) the spatial AFT age distribution, (c) the density and (d) cumulative distribution plots for the frontal moraine. The black square in (b) shows the frontal moraine (FM) location. 

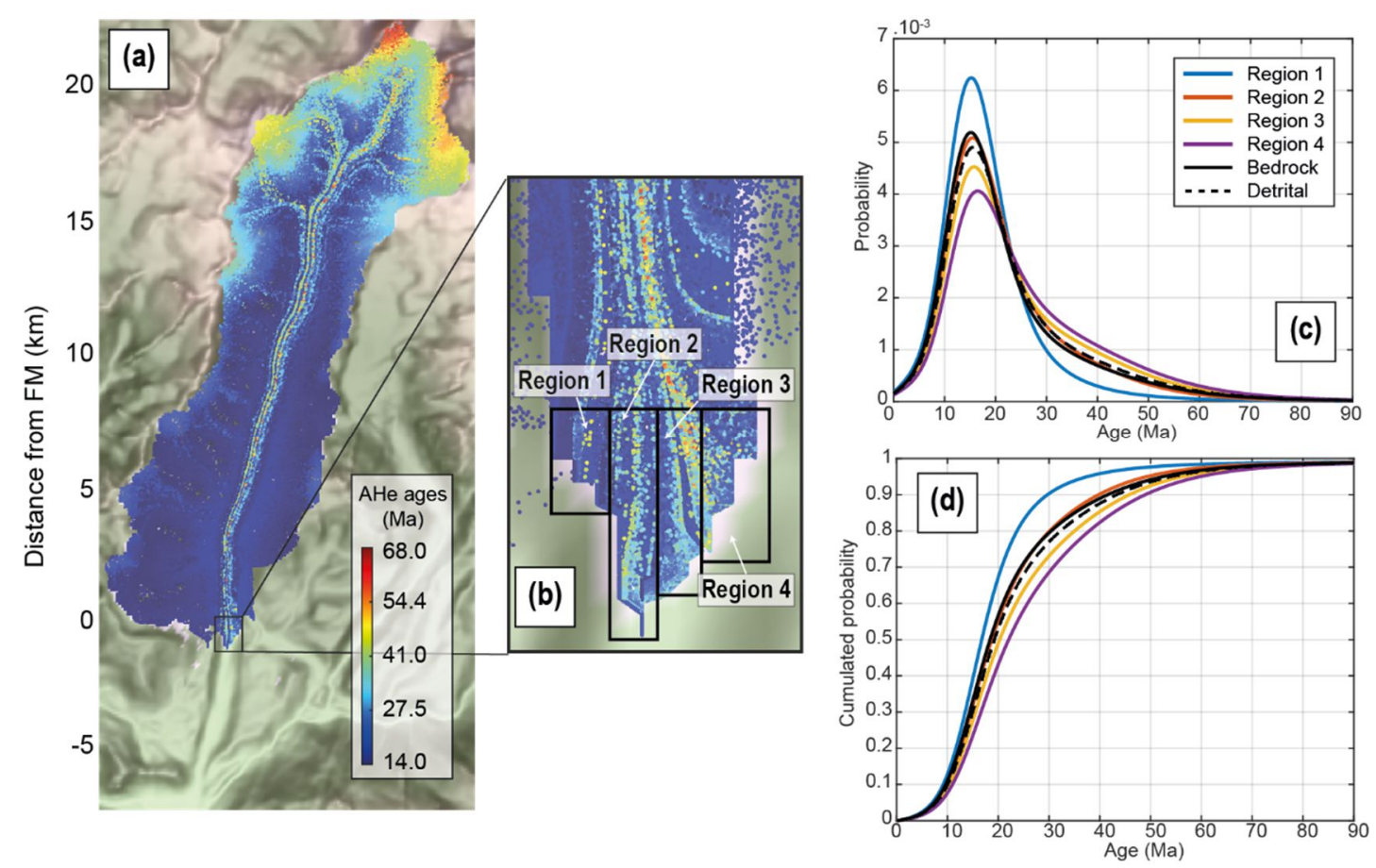

Figure S9: Detrital AFT age distribution of the four regions seen in (b, black squares) from the experiment considering uniform source of particles (a). The density plots and their cumulative distributions are shown in (c) and (d). The dashed black line is the mean detrital SPDF for the frontal moraine (FM).

\section{Local detrital sampling along a transverse transect on the main glacier}

This section brings additional information on the effect of local sampling (see Sect. 4.4. of the main text). We performed a model experiment considering uniform erosion, where the sampling approach is based on that explored in Enkelmann and Ehlers (2015), i.e. we collect particles along a transverse transect located upstream of the frontal moraine (Fig. S10). The transect is divided into five sampling sites, spaced equivalent to the resolution grid cells $(100 \mathrm{~m})$. We collect particles by randomly sample 105 particles within each site, produce a SPDF and repeat this process 10,000 times to infer a mean detrital SPDF. The mean AHe detrital SPDF and CSPDF are presented in Figure S10c-d. In addition to the detrital SPDF of the five-sampling sites we also produce a detrital SPDF resulting from the same sampling process over all the five sites combined (Fig. S10c-d, light blue curve).

Considering the detrital SPDF and CSPDF (Fig. S10c-d), we highlight the relatively high variability between the detrital SPDFs. We observe that some sites mostly sample young ages and so represent low elevations (site 1 and site 5), while others are shifted toward old ages, and so represent higher elevations (sites 2, 3 and 4). These latter sites represent the most central position of the transect and then suggest that old ages are mainly transport through the medial moraine of the main glacier. We confirm this by looking at the surface debris transport lines in Figure S10a, which shows many old ages present in the centreline (red dots). For all of the detrital SPDFs, we note a lack of ages between $\sim 5$ and $7 \mathrm{Ma}$ confirming the previous conclusion that mid-altitudes are subjected to a delay in transfer times due to storage. As expected, the mean detrital SPDF and CSPDF resulting from the sampling of the five sites combined, shows a smoothed signal of the sampling sites for the young $(\sim 3.3$ and $\sim 4.3 \mathrm{Ma})$ and old ages ( $\sim 8 \mathrm{Ma})$ peaks. Compared to the detrital SPDF and CSPDF of the frontal moraine (black dashed curves, Fig. S10c-d) most of the sites over-represent older ages, with the exception of sites 1 and 5 that over-represent younger ages, both reflecting the transport lines from different source regions. 

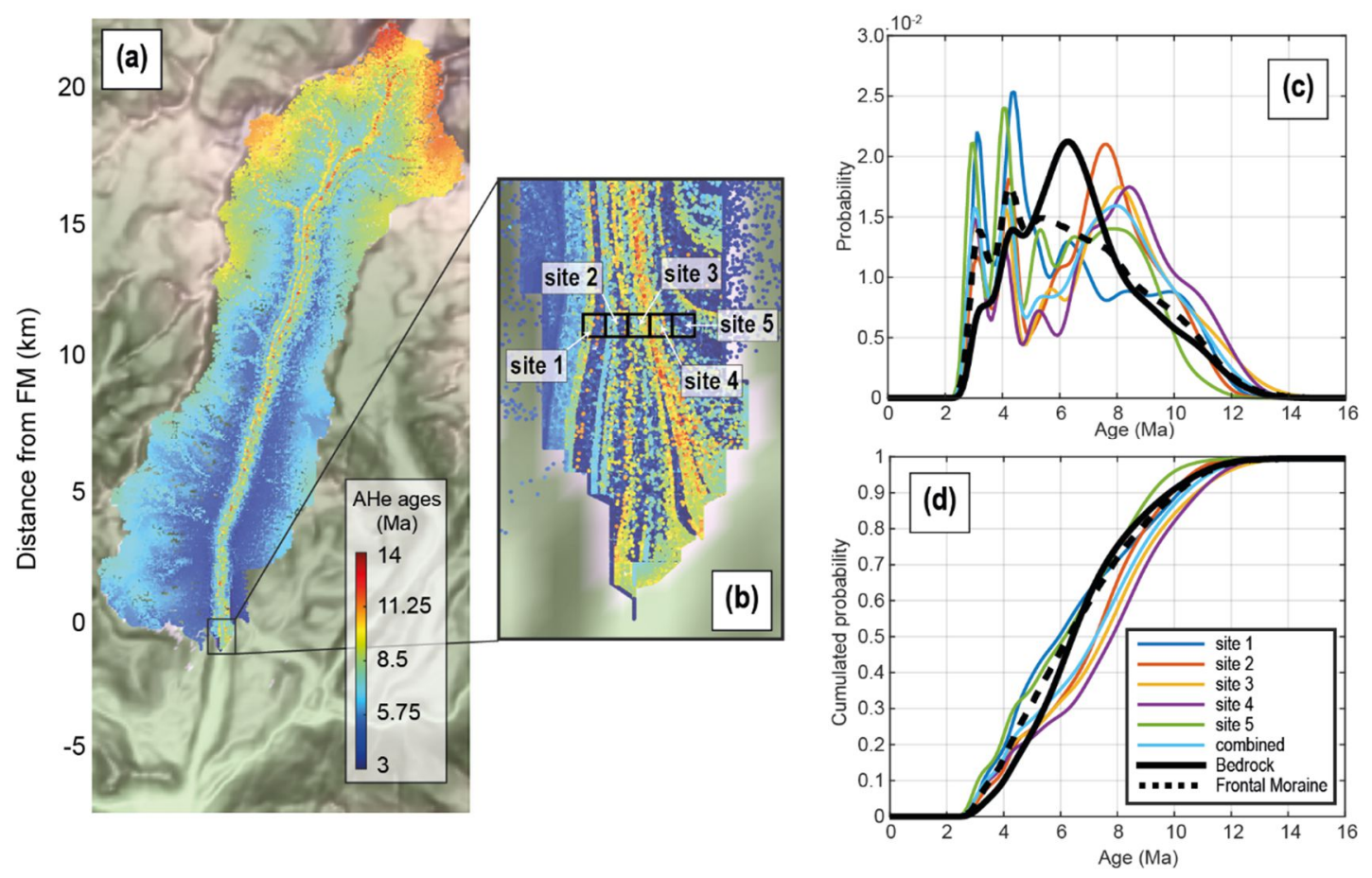

Figure S10: Detrital AHe age distribution of the five sites seen in (b, black squares) from the experiment considering uniform source of particles (a). The density plots and their cumulative distributions are shown in (c) and (d). The dashed black line is the mean detrital SPDF for the frontal moraine (FM).
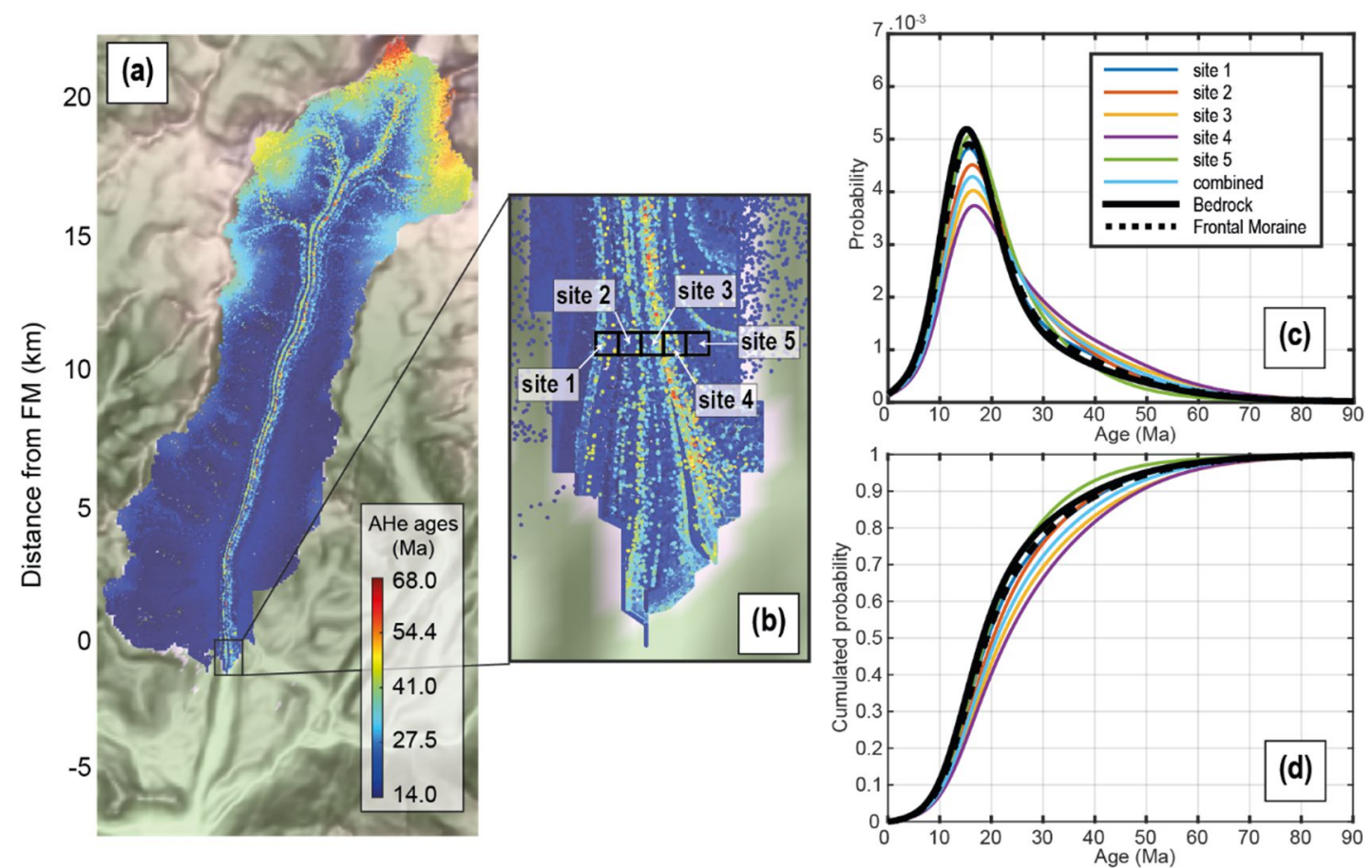

Figure S11: Detrital AFT age distribution of the five sites in (b, black squares) from the experiment considering uniform source of particles (a). The density plots and their cumulative distributions are shown in (c)) and (d). The dashed black line is the mean detrital SPDF for the frontal moraine (FM).

In contrast to the real data example of Enkelmann and Ehlers (2015), a combination of the five sites does not seems to better match the bedrock age distribution. This may result from (i) the transect considered here that does not cross the entire glacier width, therefore missing some debris flow lines (Fig. S10a), and (ii) debris transport model that has limitations (Sect. 4.1, main text), and the pattern of 
the modelled debris transport may not adequately reflect that of the real Tiedemann glacier. Indeed, in our numerical experiments particles initially located at the right-hand side of the catchment are mostly deposited in the lateral moraine because of deviated flow lines as seen in Figure S10b.

We observe a similar tendency for the AFT ages (Fig. S11), where the detrital SPDF and CSPDF of the most central sites (i.e. sites 2, 3 and 4) are biased towards older ages ( $>25 \mathrm{Ma}$ ) compared to the bedrock and detrital frontal moraine distributions. However, the deviations are generally less pronounced than for the AHe ages. Detrital age distributions of sites 1 and 5 closely match those of the bedrock and detrital frontal moraine. 